\title{
Weight change associated with third- generation adjuvant chemotherapy in breast cancer patients
}

\author{
Lubna N Chaudhary MD, ${ }^{\text {ab }}$ Sijin Wen, PhD, ${ }^{c}$ Jie Xiao MS, ${ }^{c}$ Anne K Swisher MD, ${ }^{\mathrm{d}, \mathrm{f}}$ \\ Sobha Kurian, ${ }^{\text {b }}$ and Jame Abraham, MD, FACP be
}

${ }^{a}$ Division of Hematology and Oncology, Froedtert and Medical College of Wisconsin, Milwaukee; ${ }^{\mathrm{b}}$ Section of Hematology and Oncology, ${ }^{c}$ Department of Biostatistics, ${ }^{\mathrm{d}}$ Division of Physical Therapy, West Virginia University, Morgantown; ${ }^{\mathrm{e}}$ Department of Solid Tumor Oncology, Cleveland Clinic, Cleveland, Ohio, and ${ }^{\mathrm{f}}$ Mary Babb Randolph Cancer Center, West Virginia University

Background Studies have shown that breast cancer treatment can cause an increase in weight. Weight gain during chemotherapy is usually significant and may be associated with poor survival. However, the role of third-generation chemotherapy regimens and weight gain is not well reviewed.

Methods We retrospectively analyzed the mean percentage weight change during the first year after breast cancer diagnosis in 246 patients at West Virginia University during September 2007 and October 2010. Kruskal-Wallis test and post hoc pairwise comparisons were used to assess the influence of age, histology, stage, ER/PR/HER2/neu status, menopausal status, and types of therapeutic modalities received on the percentage weight change. Kaplan-Meier method with log-rank test was used to evaluate recurrence-free survival (RFS). Local or distant recurrence and disease progression were events for RFS analysis and disease-free patients were censored at last follow-up.

Results Mean weight gain was $0.39 \%$ (SD, 0.40) of baseline body weight, 1 year after diagnosis of breast cancer. Premenopausal status was the only factor associated with significant weight gain $(+1.67 \% \mathrm{vs}-0.10 \%$ for postmenopausal patients; $P=.02)$. Stages $\geq \mathrm{III}$ was associated with significant weight loss $(-1.64 \%$ for stages III, IV vs $+0.85 \%$ for stages $0, \mathrm{I}, \mathrm{II} ; P=.02)$ and a lower RFS at 3 years and 5 years $(P<.0001)$. Higher baseline weight $(>90$ th percentile) did not have any significant impact on RFS $(0.84$ vs $0.91 ; P=.19)$. There was no significant change in weight relative to other factors.

Conclusion Our study in patients receiving third-generation adjuvant chemotherapy regimens did not show any significant change in percentage weight with chemotherapy. Premenopausal status was the only significant factor associated with weight gain. As expected, stage III or higher disease was associated with significant weight loss and lower RFS.

$\mathrm{T}$ The current obesity epidemic is a major public health concern in the United States and many other developed countries, affecting more than 66 million American adults and 400 million people worldwide. ${ }^{1}$ Obesity is related to high mortality and high risk for the development of many diseases, including cardiovascular disease, diabetes, and cancer. ${ }^{1,2}$ Breast cancer is the most common cancer among women in the world. About 4.4 million women worldwide are currently living with breast cancer, 2 million of whom are in the US, and this population is growing. ${ }^{3}$ Obesity and weight gain after diagnosis are profound issues for women with breast cancer. Weight gain is a well-documented side effect of adjuvant chemotherapy in breast cancer patients. ${ }^{4-9}$ Gains in weight usually range from 2-12 lb (1-5 kg) during the first year after diagnosis of breast cancer, ${ }^{10-18}$ although gains exceeding $22 \mathrm{lb}$ $(10 \mathrm{~kg})$ have not been uncommon. ${ }^{19}$ Numerous reasons have been suggested for this postdiagnosis weight gain, such as decreased physical activ- ity, depression, decreased basal metabolic rate, decreased serum estradiol, adjuvant treatment (especially chemotherapy), being or becoming postmenopausal after treatment, and a higher total caloric intake. ${ }^{10,12,14}$

A number of factors including tumor size, stage of breast cancer, hormone receptor status, and human epidermal growth factor receptor 2-status (HER2/ neu) are known to influence the prognosis of breast cancer. ${ }^{20,21}$ Obesity has been associated with increased incidence and mortality of breast cancer ${ }^{22}$ and may be considered one of the prognostic factors. The role of third-generation chemotherapy regimens on weight gain is not well reviewed and the precise relationship between obesity and breast cancer remains to be determined. Given the increasing number of women living with breast cancer and the growing prevalence of obesity, understanding the effect of obesity and weight gain on breast cancer prognosis is important. Therefore, we examined the body weight changes and their association with vari-

Accepted for publication March 27, 2014. Correspondence: Lubna Naaz Chaudhary, MD; lchaudhary@mcw.edu. Disclosures: The authors have no disclosures. JCSO 2014; 12:355-360. (02014 Frontline Medical Communications. DOI 10.12788/jcso.0078. 
ous factors in a sample of women who had been diagnosed with breast cancer and who were treated with third-generation chemotherapy regimens.

\section{Methods}

\section{Patient population and data collection}

Patients with newly diagnosed breast cancer treated at Mary Babb Randolph Cancer Center at West Virginia University during September 2007-October 2010 were included in our study. In all, 306 patient charts were retrospectively reviewed, of which 246 charts were included in this analysis. Charts were not included if they had incomplete information, a single clinic visit for second opinion, longer than 6 months follow-up, and not enough weights had been recorded. Patients with all stages of breast cancer were included in the analysis (stages 0-IV). Patients with history of previous cancers including breast cancer were excluded from the study.

We retrospectively analyzed the mean percentage weight change during the first year after breast cancer diagnosis in 246 patients. Data on weight included baseline weight in pounds at the time of diagnosis and at every clinic visit $3( \pm 2)$-month clinic visit for the first 12 months after their diagnosis. We chose 3 months plus or minus 2 months because it was a retrospective chart review and not every patient had a clinic visit every 3 months.

We also collected data on the patient's age, menstrual status, pathology of tumor ie, histology, grade, differentiation, receptor status (ER, PR, or HER2/neu), disease stage, and types of previous treatments including surgery, radiation, chemotherapy, and/or endocrine therapy.

The primary objective of this study was to evaluate the weight change in patients during their treatment of breast cancer with third-generation chemotherapy regimens. Primary outcome was the percentage weight change before treatment (baseline) and after treatment (12 months). We also assessed the association of weight change and recurrence-free survival (RFS) as a secondary objective. Recurrence was defined as ipsilateral, contralateral (both invasive and noninvasive) or distant metastatic disease. Local or distant recurrence and disease progression were events for RFS analysis and disease-free patients were censored at last follow-up.

Systemic treatment in neoadjuvant and adjuvant setting Most commonly used chemotherapeutic regimens for node-positive or high-risk node-negative HER2/neunegative tumors include dose-dense doxorubicin $60 \mathrm{mg} / \mathrm{m}^{2}$ intravenously (IV) on Day 1 (D1) and cyclophosphamide $600 \mathrm{mg} / \mathrm{m}^{2}$ IV D1, every 2 weeks for 4 cycles, followed by paclitaxel $80 \mathrm{mg} / \mathrm{m}^{2}$ IV weekly for 12 weeks, docetaxel $75 \mathrm{mg} / \mathrm{m}^{2}$ IV D1, doxorubicin $50 \mathrm{mg} / \mathrm{m}^{2}$ IV D1, and cyclophosphamide $500 \mathrm{mg} / \mathrm{m}^{2}$ IV D1 every 3 weeks for 6 cycles, docetaxel $75 \mathrm{mg} / \mathrm{m}^{2}$ IV D1 and cyclophosphamide $600 \mathrm{mg} / \mathrm{m}^{2}$ IV D1 every 3 weeks for 4 cycles.

HER2/neu-positive tumors are usually treated with docetaxel $75 \mathrm{mg} / \mathrm{m}^{2}$ IV D1 every 3 weeks for 6 cycles, carboplatin AUC6 IV D1 every 3 weeks for 6 cycles, and trastuzumab $4 \mathrm{mg} / \mathrm{kg}$ loading dose, followed by $2 \mathrm{mg} / \mathrm{kg}$ IV weekly during chemotherapy; then $6 \mathrm{mg} /$ $\mathrm{kg}$ IV every 3 weeks, for a total of 1 year; or dose-dense doxorubicin, cyclophosphamide, and paclitaxel regimen with trastuzumab. Endocrine therapy includes tamoxifen $20 \mathrm{mg}$ daily (at least 5 years) for premenopausal women and aromatase inhibitors for postmenopausal women (5 years).

\section{Statistical analysis}

Descriptive statistics and exploratory data analyses were performed to summarize patient characteristics. Categorical data are described using contingency tables. Continuously scaled measures were summarized by mean and standard error, median and interquartile range. Kruskal-Wallis test and post hoc pairwise comparisons were used to assess the influence of age; histology; stage; ER, PR, or HER2/ neu status; menopausal status; and types of therapeutic modalities received on the percentage weight change. Kaplan-Meier method with log-rank test was used to evaluate RFS. In addition, multivariate (multiple covariates) linear regression was used to identify an appropriate subset of independent variables/covariates with a significant impact on weight changes. Covariates included disease type or diagnosis, histology, stage, treatments, and other medical conditions. All statistical tests with two-sided $P<.05$ were considered statistically significant.

\section{Results \\ Patient characteristics}

Baseline characteristics of the patients included in this chart review and the details on their chemotherapy regimens are shown in Table 1. Of 246 patients, 143 were between 40 and 60 years old. More than half of the patients $(n=174)$ had invasive ductal carcinoma and 141 patients were ER/PR-positive and HER2/ neu-negative.

\section{Weight change during treatment}

Mean weight gain was $0.39 \%( \pm 0.40)$ at 1 year after the diagnosis of breast cancer. Premenopausal status was the only factor associated with significant weight gain $(+1.67 \%$ vs $-0.10 \%$ for postmenopausal patients; $P=.019)$. Stage of III or higher was associated with significant weight loss $(-1.64 \%$ for stages III/IV vs $+0.85 \%$ for stages $0 / \mathrm{I} / \mathrm{II}$; $P=.018)$. Menstrual status and stage were the only 2 factors associated with significant weight change - there was no significant change in weight relative to age, histology, 
TABLE 1 Baseline patient characteristics

\begin{tabular}{|c|c|c|c|}
\hline Characteristic & $\begin{array}{c}\text { No. of patients, } \\
n(\%) \\
(\mathbf{N}=\mathbf{2 4 6})\end{array}$ & Characteristic & $\begin{array}{c}\text { No. of patients, } \\
n(\%) \\
(N=246)\end{array}$ \\
\hline Age, y & & Chemotherapy & \\
\hline$<40$ & $12(4.8)$ & No & $109(44.3)$ \\
\hline $40-60$ & $143(58.1)$ & Yes & $137(55.7)$ \\
\hline$>60$ & $91(37.1)$ & Neoadjuvant & $36(14.6)$ \\
\hline Histology & & $\mathrm{AC} \rightarrow \mathrm{T}$ & 19 \\
\hline DCIS & $47(19.1)$ & $\mathrm{AC} \rightarrow>\mathrm{T}+\mathrm{H}$ & 7 \\
\hline IDC & $174(70.7)$ & $\mathrm{TAC}+\mathrm{Av}$ & 7 \\
\hline ILC & $22(8.9)$ & $\mathrm{TCH}$ & 2 \\
\hline Others & $3(1.22)$ & TC & 1 \\
\hline Stage & & Adjuvant & $101(41.1)$ \\
\hline 0 & 45 (18.3) & $\mathrm{AC}$ & 6 \\
\hline I & $84(34.1)$ & $A C->T+A v$ & 8 \\
\hline$\|$ & $72(29.3)$ & $A C \rightarrow T$ & 10 \\
\hline III & $33(13.4)$ & $\mathrm{AC} \rightarrow \mathrm{T}+\mathrm{H}$ & 4 \\
\hline IV & $12(4.9)$ & $\mathrm{TC}$ & 27 \\
\hline ER/PR and HER2-neu & & TAC & 12 \\
\hline Positive and negative & $141(57.3)$ & $\mathrm{TCH}$ & 14 \\
\hline Positive and positive & 19 (7.7) & Others & 20 \\
\hline Negative and negative & 32 (13.0) & Surgery & \\
\hline Negative and positive & 8 (3.3) & Lumpectomy & $120(48.8)$ \\
\hline Differentiation/grade & & Mastectomy & $117(47.6)$ \\
\hline Poor/high & $121(49.2)$ & Radiation therapy & \\
\hline Moderate/intermediate & $96(39.0)$ & No & $107(43.5)$ \\
\hline Well/low & $24(9.7)$ & Yes & $136(55.3)$ \\
\hline Menstrual status & & Endocrine therapy & \\
\hline Postmenopausal & $178(72.4)$ & Aromatase inhibitors & $122(50.1)$ \\
\hline Premenopausal & $68(27.6)$ & Tamoxifen & $54(22.1)$ \\
\hline
\end{tabular}

DCIS, ductal carcinoma in situ; IDC, invasive ductal carcinoma; ILC, invasive lobular carcinoma; $A C->T$; doxorubicin, cyclophosphamide, paclitaxel; $H$, trastuzumab; TAC, docetaxel, doxorubicin, cyclophosphamide; TCH, docetaxel, carboplatin, trastuzumab; Av, bevacizumab; TC, docetaxel, cyclophosphamide.

receptor status, type of surgery, and chemotherapy or endocrine therapy (Table 2 ).

\section{Recurrence-free survival}

Recurrence-free survival analysis showed that stages III and IV disease was associated with significantly lower RFS at 3 years and 5 years $(P<.0001)$, which is an expected finding because node-positive and higher-stage patients have a higher risk of local and distant recurrence and poor prognosis. Per the Kaplan-Meir analysis, higher baseline weight (> 90th percentile) did not have any significant impact on $\operatorname{RFS}(P=.19)$.

\section{Discussion}

There has been significant interest in weight change in regard to breast cancer treatment, and its association with the risk of breast cancer recurrence and breast cancer mortality. Adjuvant chemotherapy offers considerable benefits in terms of improvement in overall survival in patients with breast cancer. However, in addition to the expected side effects of chemotherapy, such as nausea, alopecia, fatigue, and cytopenias, weight gain is also known to occur in many patients. The reasons for weight gain are likely multifactorial, including changes in activity level, menopausal status, endocrine manipulation, diet, metabolism, 
TABLE 2 Mean and median of weight change percentages by 12 months

\begin{tabular}{|c|c|c|c|c|}
\hline \multirow[b]{3}{*}{ Overall } & \multirow{2}{*}{$\begin{array}{c}\text { No. of } \\
\text { patients, } \\
\text { n (\%) }\end{array}$} & \multicolumn{2}{|c|}{$\begin{array}{c}\text { Weight percentage } \\
\text { change by } 12 \text { months, \% }\end{array}$} & \multirow{3}{*}{$P$ value } \\
\hline & & Mean (SD) & Median (IQR) & \\
\hline & 246 & $0.39(0.40)$ & $0.54(5.49)$ & \\
\hline \multicolumn{5}{|l|}{ Age, y } \\
\hline$<40$ & $12(4.8)$ & $3.62(1.77)$ & $2.60(9.34)$ & \multirow[t]{3}{*}{.213} \\
\hline $40-60$ & $143(58.1)$ & $0.46(0.58)$ & $0.60(5.84)$ & \\
\hline$>60$ & $91(37.1)$ & $-0.14(0.56)$ & $0(5.15)$ & \\
\hline
\end{tabular}

$\begin{array}{lccl}\text { Histology } & & & .392 \\ \text { DCIS } & 47(19.1) & 0.44(0.82) & 0.30(5.13) \\ \text { IDC } & 174(70.7) & 0.14(0.51) & 0.45(5.46) \\ \text { ILC } & 22(8.9) & 1.59(0.87) & 1.16(4.75)\end{array}$

Stage

018

$0 / 1 / 11$

$201(81.7)$

$0.85(0.41)$

$0.83(4.64)$

III/IV

45 (18.3)

$-1.64(1.22)$

-1.63 (10.54)

\section{ER/PR and HER2-neu}

Positive and negative

$141(57.3)$

$0.20(0.58)$

19 (7.7)

$0.38(1.29)$

32 (13.0)

$0.93(1.00)$

8 (3.3)

$1.25(2.21)$

Negative and positive

Differentiation/grades

Poor/high

$121(49.2)$

$0.75(0.54)$

$120(48.8)$

$0.15(0.61)$

intermediate/well/low

\begin{tabular}{|c|c|c|c|c|}
\hline \multicolumn{4}{|l|}{ Menstrual status } & \multirow[t]{2}{*}{0.019} \\
\hline Postmenopausal & $178(72.4)$ & $-0.10(0.48)$ & $0.12(5.04)$ & \\
\hline Premenopausal & $68(27.6)$ & $1.67(0.74)$ & $2.23(6.87)$ & \\
\hline Chemotherapy & & & & .801 \\
\hline No & $109(44.3)$ & $0.46(0.48)$ & $0.52(5.23)$ & \\
\hline Yes & $137(55.7)$ & $0.33(0.62)$ & $0.60(5.51)$ & \\
\hline Surgery & & & & .654 \\
\hline Lumpectomy & $120(48.8)$ & $0.59(0.56)$ & $0.48(5.28)$ & \\
\hline Mastectomy & $117(47.6)$ & $1.28(0.80)$ & $1.08(4.57)$ & \\
\hline Radiation therapy & & & & .297 \\
\hline No & $107(43.5)$ & $0.64(0.57)$ & 0.83 (4.69) & \\
\hline Yes & $136(55.3)$ & $0.20(0.57)$ & $0.39(5.90)$ & \\
\hline Endocrine therapy & & & & .532 \\
\hline Aromatase inhibitors & $122(50.1)$ & $0.25(0.58)$ & $0.54(4.94)$ & \\
\hline Tamoxifen & $54(22.1)$ & $0.92(0.76)$ & $0.97(5.13)$ & \\
\hline
\end{tabular}

DCIS, ductal carcinoma in situ; ER, estrogen receptor; HER-neu, human epidermal growth factor receptor 2; IDC, invasive ductal carcinoma; ILC, invasive lobular carcinoma; IQR, interquartile range; PR, progesterone receptor; SD, standard deviation and mood. Studies generally suggest that greater prediagnosis body mass index and weight gain during treatment is associated with an increased risk of mortality risk and of recurrence, particularly in premenopausal women. ${ }^{23-31}$

A meta-analysis of 43 studies examining the relationship between weight at the time of breast cancer diagnosis and prognosis in women with early-stage breast cancer demonstrated a 33\% increase in the risk of breast cancer related and overall mortality in obese compared with non-obese women. ${ }^{32} \mathrm{~A}$ recent analysis of 3 ECOG (Eastern Cooperative Oncology Group) trials evaluated the relationship between body mass index and clinical outcomes in women with stages I-III breast cancer who were treated with adjuvant doxorubicin-containing chemotherapy. Obesity was associated with inferior disease-free survival and overall survival specifically in hormone receptor-positive, HER2/neu-negative disease. ${ }^{33}$ It is however important to mention that all of those trials were completed before trastuzumab was approved as adjuvant therapy for HER2-positive disease. One hypothesis that might explain the poor survival seen in obese breast cancer patients is that adipose tissue and adipose stem cells are associated with the up-regulation of a number of cellular proliferation pathways that in turn influence breast cancer tumor genesis and tumor progression. ${ }^{34}$ Consequently, obese patients may have increased tumor cell proliferation and metastasis because of an undefined adipokine effect on tumor cells..$^{25}$

Unlike previous studies, our study of patients using third-generation chemotherapy regimens did not show any significant change in mean percentage weight with chemotherapy. Premenopausal status was the only factor associated with weight gain. Stages III and IV dis- 
ease was associated with significant weight loss and lower RFS. In contrast to the published literature, our study did not show a significant increase in weight with chemotherapy, and most women who gained weight during treatment were able to lose it within first year after diagnosis, resulting in only $0.39 \%$ mean weight change. We also found that higher baseline weight was not associated with worse prognosis in our patients and had no significant effect on RFS. This is in contrast to findings in the Nurses Health Study, which reported positive association between obesity at diagnoses and breast cancer recurrence and all-cause mortality. ${ }^{35}$ These differences in results are most likely related to the smaller sample size of our study. Longer follow-up may be needed to confirm the RFS results of our study and the association of higher baseline weights and prognosis. Given the limitations of our study, we think it is important to continue encouraging women to maintain a healthy weight after breast cancer diagnosis.

There is some evidence that postdiagnosis weight reduction modifies and improves prognosis. The effect of dietary fat reduction in early-stage breast cancer has been evaluated in 2 clinical trials, WINS (Women's Intervention Nutrition Study) ${ }^{36}$ and WHEL (Women's Healthy Eating and Living). ${ }^{37} \mathrm{~A}$ reduction in dietary fat was associated with modest average weight loss of $6 \mathrm{lb}(13.2 \mathrm{~kg})$ and with reduced recurrence in the WINS trial, but was not observed in the WHEL trial, in which dietary intervention did not produce weight loss. Recently, at least 3 RCTs designed to evaluate the impact of weight loss interventions and counseling for obese breast cancer patients (NCT01482702, NCT00869466, NCT00872677 clinicaltrials.gov) have been completed. Further studies tailored to the unique psychological, nutritional and physical needs of breast cancer survivors by providing them with lifestyle and behavioral interventions are ongoing (NCT01630499, NCT01871116 clinicaltrials.gov). The results of these studies will give us further insight into the association of weight changes and breast cancer prognosis.

In summary, our study showed no significant change in mean percentage weight with third-generation chemotherapy agents in our study population as a whole. However, weight gain was observed in premenopausal women. Menopausal status was the only significant factor associated with weight gain whereas obesity at diagnosis was not associated with worse prognosis. Prospective studies to evaluate the weight changes with third-generation chemotherapy regimens are warranted to determine relationships between chemotherapy, weight change and breast cancer prognosis.

\section{Acknowledgment}

This article was presented as a poster at ASCO Breast Cancer Symposium, San Francisco, in September 2013.

\section{References}

1. World Health Organization. Obesity and overweight. http://www. who.int/mediacentre/factsheets/fs311/en/. Updated august 2014. Accessed October 13, 2013.

2. Renehan AG, Tyson M, Egger M, Heller RF, Zwahlen M. Bodymass index and incidence of cancer: a systematic review and metaanalysis of prospective observational studies. Lancet. 2008;371:569578.

3. American Cancer Society. Breast cancer facts and figures. http:// www.cancer.org/research/cancerfactsstatistics/breast-cancer-factsfigures. Updated 2012-2013. Accessed October 13, 2013.

4. Cheney CL, Mahloch J, Freeny P. Computerized tomography assessment of women with weight changes associated with adjuvant treatment for breast cancer. Am J Clin Nutr. 1997;66:141-146.

5. DeGeorge D, Gray JJ, Fetting JH, Rolls BJ. Weight gain in patients with breast cancer receiving adjuvant treatment as a function of restraint, disinhibition, and hunger. Oncol Nurs Forum. 1990;17(3 Suppl):23-8; discussion 28-30.

6. Dixon JK, Moritz DA, Baker FL. Breast cancer and weight gain: an unexpected finding. Oncol Nurs Forum. 1978;5:5-7.

7. Foltz AT. Weight gain among stage II breast cancer patients: A study of five factors. Oncol Nurs Forum. 1985;12:21-26.

8. Huntington MO. Weight gain in patients receiving adjuvant chemotherapy for carcinoma of the breast. Cancer. 1985;56:472-474.

9. Knobf MK, Mullen JC, Xistris D, Moritz DA. Weight gain in women with breast cancer receiving adjuvant chemotherapy. Oncol Nurs Forum. 1983;10:28-33.

10. Goodwin PJ. Weight gain in early-stage breast cancer: Where do we go from here? J Clin Oncol. 2001;19:2367-2369.

11. Levine EG, Raczynski JM, Carpenter JT. Weight gain with breast cancer adjuvant treatment. Cancer. 1991;67:1954-1959.

12. Goodwin PJ, Ennis M, Pritchard KI, et al. Adjuvant treatment and onset of menopause predict weight gain after breast cancer diagnosis. J Clin Oncol. 1999;17:120-129.

13. Demark-Wahnefried W, Peterson BL, Winer EP, et al. Changes in weight, body composition, and factors influencing energy balance among premenopausal breast cancer patients receiving adjuvant chemotherapy. J Clin Oncol. 2001;19:2381-2389.

14. Demark-Wahnefried W, Rimer BK, Winer EP. Weight gain in women diagnosed with breast cancer. J Am Diet Assoc. 1997;97:519526,529; quiz 527-8.

15. Heasman KZ, Sutherland HJ, Campbell JA, Elhakim T, Boyd NF. Weight gain during adjuvant chemotherapy for breast cancer. Breast Cancer Res Treat. 1985;5:195-200.

16. Aslani A, Smith RC, Allen BJ, Pavlakis N, Levi JA. Changes in body composition during breast cancer chemotherapy with the CMF-regimen. Breast Cancer Res Treat. 1999;57:285-290.

17. Irwin ML, McTiernan A, Baumgartner RN, et al. Changes in body fat and weight after a breast cancer diagnosis: Influence of demographic, prognostic, and lifestyle factors. J Clin Oncol. 2005;23:774782 .

18. Makari-Judson G, Judson CH, Mertens WC. Longitudinal patterns of weight gain after breast cancer diagnosis: Observations beyond the first year. Breast J. 2007;13:258-265.

19. Demark-Wahnefried W, Winer EP, Rimer BK. Why women gain weight with adjuvant chemotherapy for breast cancer. J Clin Oncol. 1993;11:1418-1429.

20. Cianfrocca M, Goldstein LJ. Prognostic and predictive factors in early-stage breast cancer. Oncologist. 2004;9:606-616.

21. Slamon DJ, Clark GM, Wong SG, Levin WJ, Ullrich A, McGuire WL. Human breast cancer: Correlation of relapse and survival with amplification of the HER-2/neu oncogene. Science. 1987;235:177182.

22. van den Brandt PA, Spiegelman D, Yaun SS, et al. Pooled analysis of prospective cohort studies on height, weight, and breast cancer risk. Am J Epidemiol. 2000;152:514-527.

23. Berclaz G, Li S, Price KN, et al. Body mass index as a prognostic feature in operable breast cancer: The international breast cancer study group experience. Ann Oncol. 2004;15:875-884.

24. Zhang S, Folsom AR, Sellers TA, Kushi LH, Potter JD. Better breast 
cancer survival for postmenopausal women who are less overweight and eat less fat. the iowa women's health study. Cancer. 1995;76:275283.

25. Daling JR, Malone KE, Doody DR, Johnson LG, Gralow JR, Porter PL. Relation of body mass index to tumor markers and survival among young women with invasive ductal breast carcinoma. Cancer. 2001;92:720-729.

26. Rock CL, Demark-Wahnefried W. Nutrition and survival after the diagnosis of breast cancer: A review of the evidence. J Clin Oncol. 2002;20:3302-3316.

27. Chlebowski RT, Aiello E, McTiernan A. Weight loss in breast cancer patient management. J Clin Oncol. 2002;20:1128-1143.

28. Petrelli JM, Calle EE, Rodriguez C, Thun MJ. Body mass index, height, and postmenopausal breast cancer mortality in a prospective cohort of US women. Cancer Causes Control. 2002;13:325-332.

29. Loi S, Milne RL, Friedlander ML, et al. Obesity and outcomes in premenopausal and postmenopausal breast cancer. Cancer Epidemiol Biomarkers Prev. 2005;14:1686-1691.

30. Whiteman MK, Hillis SD, Curtis KM, McDonald JA, Wingo PA, Marchbanks PA. Body mass and mortality after breast cancer diagnosis. Cancer Epidemiol Biomarkers Prev. 2005;14:2009-2014.

31. Cleveland RJ, Eng SM, Abrahamson PE, et al. Weight gain prior to diagnosis and survival from breast cancer. Cancer Epidemiol Biomarkers Prev. 2007;16:1803-1811.

32. Protani M, Coory M, Martin JH. Effect of obesity on survival of women with breast cancer: Systematic review and meta-analysis. Breast Cancer Res Treat. 2010;123:627-635.

33. Sparano JA, Wang M, Zhao F, et al. Obesity at diagnosis is associated with inferior outcomes in hormone receptor-positive operable breast cancer. Cancer. 2012;118:5937-5946.

34. Calle EE, Kaaks R. Overweight, obesity and cancer: Epidemiological evidence and proposed mechanisms. Nat Rev Cancer. 2004;4:579591.

35. Kroenke CH, Chen WY, Rosner B, Holmes MD. Weight, weight gain, and survival after breast cancer diagnosis. J Clin Oncol. 2005;23:1370-1378.

36. Chlebowski RT, Blackburn GL, Thomson CA, et al. Dietary fat reduction and breast cancer outcome: Interim efficacy results from the women's intervention nutrition study. J Natl Cancer Inst. 2006;98:1767-1776.

37. Pierce JP, Natarajan L, Caan BJ, et al. Influence of a diet very high in vegetables, fruit, and fiber and low in fat on prognosis following treatment for breast cancer: The women's healthy eating and living (WHEL) randomized trial. J Am Med Assoc. 2007;298:289-298. 